\title{
Upper gastrointestinal endoscopic findings and prevalence of Helicobacter pylori infection among adult patients with dyspepsia in northern Tanzania
}

\author{
SEGNI M. AYANA ${ }^{1^{*}}$, BIRGITTA SWAI ${ }^{2}$, VENANCE P. MARO ${ }^{1}$ and GIBSON S. KIBIKI ${ }^{1,3}$ \\ ${ }^{1}$ Department of Internal Medicine, Kilimanjaro Christian Medical Centre, Moshi, Tanzania \\ ${ }^{2}$ Department of Clinical Pathology, Kilimanjaro Christian Medical Centre, Moshi, Tanzania \\ ${ }^{3}$ Kilimanjaro Clinical Research Institute, Kilimanjaro Christian Medical Centre, Moshi, Tanzania
}

\begin{abstract}
Dyspepsia is a common presenting complaint of various upper gastrointestinal disorders. The symptoms of causes of dyspepsia often overlap and this makes etiological diagnosis difficult. Endoscopy is the ideal procedure for identifying organic diseases of the foregut. Helicobacter pylori infection is associated with various upper gastrointestinal pathologies. A cross-sectional study was conducted to determine endoscopic findings and $\mathrm{H}$. pylori status in two hundred and eight consecutive dyspeptic adult patients between June 2009 and April 2010 at Kilimanjaro Christian medical Centre, a referral and teaching hospital in northern Tanzania. The most commonly identified endoscopic findings were gastritis (61.10\%), Gastroesophageal reflux disease (GERD) (57\%), and Peptic ulcer disease (PUD) (24.1\%). Gastric cancer was identified in $6.7 \%$ of patients and all of them were aged 40 years and above $(p=0.00)$. H. pylori infection was detected in $65 \%(n=130)$ of patients. $H$. pylori infection was present in $57 \%(n=24)$ of patients who were tested within six months after eradication therapy. Gastritis and duodenal ulcer were statistically significantly associated with $H$. pylori $(p<0.001)$. No association was found between GERD and H. pylori infection ( $p>0.05$ ). Gastritis, GERD, and PUD are the leading causes of dyspepsia. H. pylori infection is present in significant proportion of dyspeptic patients. Patients with Gastritis and PUD should undergo empirical eradication therapy if a confirmatory test is not available. Patients with dyspepsia who are over 40 years of age should undergo Endoscopy (EGD) for initial work up. Study on antimicrobial susceptibility pattern of $\mathrm{H}$. pylori is recommended to guide choices for evidence based treatment option.
\end{abstract}

Keywords: endoscopy, dyspepsia, Helicobacter pylori, gastrointestinal tract, Tanzania

\section{Introduction}

Dyspepsia is a common presenting complaint of various upper gastrointestinal disorders. The causes of dyspepsia are many and the major ones include gastroduodenitis, PUD, malignancies, esophagitis, parasitic infestations, and functional dyspepsia. The distribution of these upper gastrointestinal lesions varies significantly in different countries and within geographic locations in the same nation (Tytgat, 2002; Kibiki et al., 2006). Furthermore, symptoms of these causes often overlap and this makes etiological diagnosis difficult. Endoscopy is the ideal procedure for identifying organic diseases of the foregut, but this service is yet to be widely available in developing countries including Tanzania. H. pylori infection is known to be among the most common human infections worldwide; approximately $50 \%$ of the world's population is infected with $\mathrm{H}$. pylori (Brown, 2000; Go, 2002). $\mathrm{H}$. pylori infection is associated with various upper gastrointestinal pathologies such gastritis, peptic ulcers and gastric cancer (Graham, 1994; Blaser, 1995; Go, 2002; Marshall \& Winsdor, 2005). Because of the strong association between this gram negative bacterium infection and gastrointestinal diseases and its high prevalence rate in developing countries (Suerbaum \& Michetti 2002; Frenck \& Clemens, 2003; Kazuo et al., 2004; Xia et al., 2005; Tkachenko et al., 2007; Kate et al., 2009)., H. pylori infection is among the leading gastroenterological public health problems in developing countries (Kate et al., 2009).

H. pylori infection can be diagnosed either by invasive tests which require endoscopy and gastric biopsy (e.g., rapid urease test) or by noninvasive tests (e.g. urea breathe test). The choice of

\footnotetext{
* Correspondence: Dr. Segni Mekonnen Ayana, E-mail: segni1998@yahoo.com
} 
test depends to a large extent on availability and cost. Other important factors are: clinical situation, population prevalence of infection, pretest probability of infection, differences in test performance, and factors that may influence the test results, such as the use of anti-secretory treatment and antibiotics. The gold standard (endoscopy with rapid urease testing) is not readily available in all parts of the world. In some regions where $\mathrm{H}$. pylori prevalence is very high, diagnostic tests for the infection are not cost-effective and the decision to treat must then assume the presence of the infection. In low-resource communities, considerations of precision and sensitivity may sometimes be traded against costs and the availability of resources. Therefore, it is recommended to do empirical eradication therapy than do nothing (World Gastroenterology Organization Guidelines, 2010; Jemilohun et al., 2013). Eradication therapy heals peptic ulcers, prevent relapses and thus cure the disease in most patients (Hopkins et al., 1996; Gaby, 2001; Yi-Chia et al., 2008). Some studies suggest eradication of the organism reverses some low-grade mucosal associated lymphoid tissue (MALT) lymphomas of the stomach (Stolte et al., 2002; Fischbach et al., 2004) and early treatment of $\mathrm{H}$. pylori infection before the development of gastric atrophy or intestinal metaplasia prevents the development of gastric cancer (Yi-Chia et al., 2008).

An optimal diagnostic approach to patients with dyspepsia continues to be debated and there is no single algorithm that would be applicable in all geographic settings. In resource limited settings, especially when access to endoscopy service and tests for $\mathrm{H}$. pylori are limited, it is very important for clinicians to know common causes of dyspepsia and frequency of $\mathrm{H}$. pylori infection. Thus, the aim of this study is to determine the common upper gastrointestinal lesions and the prevalence of $\mathrm{H}$. pylori infection among dyspeptic patients. This study would assist clinicians in choosing an optimal diagnostic and management approach to dyspeptic patients in our setting and similar institutions. It will also contribute evidence for development of a guideline for the management of dyspepsia and provide valuable information for similar studies in the future.

\section{Materials and Methods}

\section{Study area}

This cross-sectional study was conducted at the Department of Internal Medicine of Kilimanjaro Christian Medical Centre (KCMC). KCMC is a referral, research and teaching hospital, located in Moshi in northern Tanzania. The hospital caters for northern and central zones of Tanzania and has the catchment population of over 15 million. The hospital has 25 clinical departments and an official capacity of 450 beds of which 88 beds are committed to the department of internal medicine. There is an endoscopy unit within the department.

\section{Study design and data collection}

Consecutive 208 patients ( $\geq 13$ years) with dyspeptic symptoms who presented to out-patient medical clinic or admitted to hospital or referred for endoscopy between June 2009 and April 2010 were recruited to participate in the study. Only patients who signed informed written consent and who had at least one of the following three symptoms; epigastric pain or burning, early satiety and postprandial fullness and who had no contraindications to undergo EGD were included. The study was approved by the institution's research and ethics committee. Upper Gl endoscopy was performed by experienced endoscopist using video endoscope Olympus-exera 160 series and findings were coded and documented on standardized data collection sheet. Antral biopsy was taken from the lesser or greater curvature of the stomach and rapid urease test (CLOTest ${ }^{\circledR}$ ) was performed to test for $\mathrm{H}$. pylori infection. In selected cases such as suspected malignancy, at least 4 biopsy specimens were preserved in 10\% formalin, labeled appropriately and dispatched for histological examination by a histopathologist. 


\section{Data analysis}

Data was analyzed using SPSS version 15. Chi-square test was used to test the association between variables and a $p$ value of $\leq 0.05$ was considered indicative of statistically significant difference. The likelihood of occurrence of events was tested by odds ratio at $95 \%$ confidence level.

\section{Results}

Characteristics of the study population and presenting symptoms and signs

During the study period, 208 patients underwent endoscopy due to dyspepsia. The female to male ratio was 1.1 to 1 . The age range (median) was 13 to 95 (48) years.

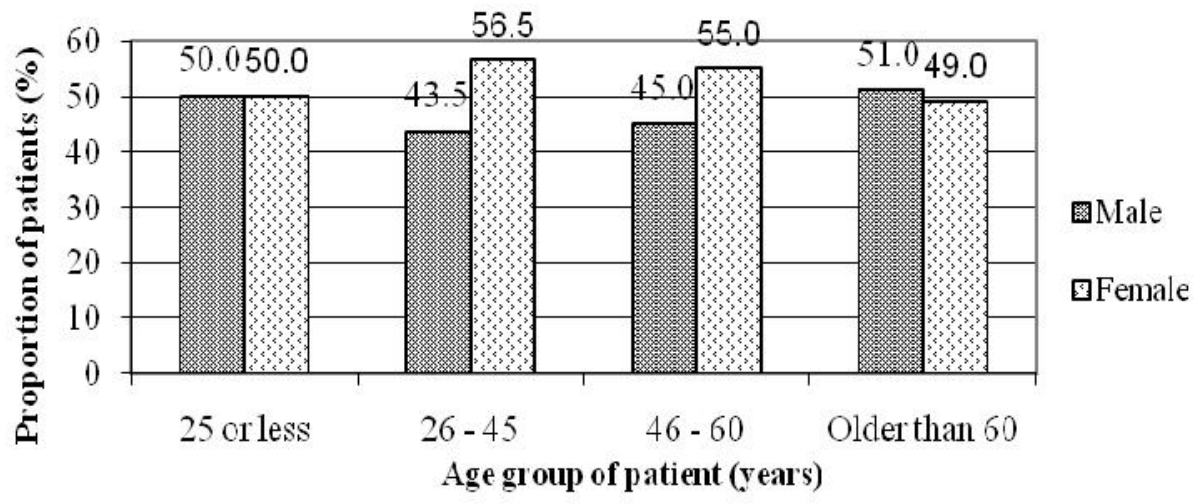

Figure 1: Age and sex distribution of patients with dyspepsia $(n=208)$

Epigastric pain was reported by $179(86.1 \%)$ of patients with dyspepsia. Other presenting symptoms were heart burn (58.2\%), nausea (46.6\%), and early satiety (41.3\%). Duration of symptoms ranged from 2 days to 20 years. Epigastric tenderness was elicited in $57(27.4 \%)$ patients.

Table 1: Distribution of endoscopic findings in patients with dyspepsia $(\mathrm{N}=208)$ (Some patients had two or more endoscopic findings).

\begin{tabular}{lll}
\hline Endoscopic diagnosis & Number & Percent \\
\hline Gastritis & 127 & 61.1 \\
Gastroesophageal reflux disease & 122 & 58.7 \\
Duodenal ulcer & 38 & 18.3 \\
Duodenitis & 32 & 15.4 \\
Sliding Hiatus hernia & 14 & 6.7 \\
Gastric cancer & 14 & 6.7 \\
Gastric ulcer & 12 & 5.8 \\
Esophageal cancer & 4 & 1.9 \\
Other & 9 & 4.3 \\
Normal & 12 & 5.8 \\
\hline
\end{tabular}

\section{Endoscopic findings}

When examined by EGD, 196 (94.2\%) of the 208 subjects had abnormal endoscopic findings. The most commonly identified endoscopic findings were gastritis seen in 127 (61.10\%) patients, Gastroesophageal reflux disease (GERD) in 122 (58.7\%) patients, and peptic ulcer (duodenal and gastric 
ulcer) disease in $50(24.1 \%)$ patients. Histologically confirmed gastric cancer was diagnosed in 14 (6.7\%) patients with dyspepsia and all patients with Gastric cancer were aged 40 years and above. The association of age above 40 years and gastric cancer was statistically significant $(p<0.0001)$ (Table 1).

\section{Frequency of $\mathrm{H}$. pylori Infection among Patients with Dyspepsia}

Rapid Urease Test (RUT) was done to 205 patients but the test was inconclusive in 5 patients and therefore these were excluded from analysis. In three out of 208 patients, biopsy was contraindicated on medical grounds such as bleeding diathesis. Of the remaining 200 patients, 130 (65.0\%) had positive RUT result indicating $H$. pylori infection. Among the 200 patients, $42(21.0 \%)$ reported that they had undergone $H$. pylori eradication therapy (within the past 6 months from the date of examination) for a median duration of 10 days. The regimens used for eradication were combination of proton pump inhibitors with Nitroimidazole and Amoxicillin (43\%), or Nitroimidazole and Macrolides (33\%), or Macrolides and Amoxicillin (11\%), or various combinations of the above with doxycycline (13\%). Of these 42 patients, $24(57.1 \%)$ had positive RUT results. There was no significant difference in RUT results of patients who underwent eradication therapy and who did not $(p=0.230)$ $\mathrm{m}$ (Figure 2).

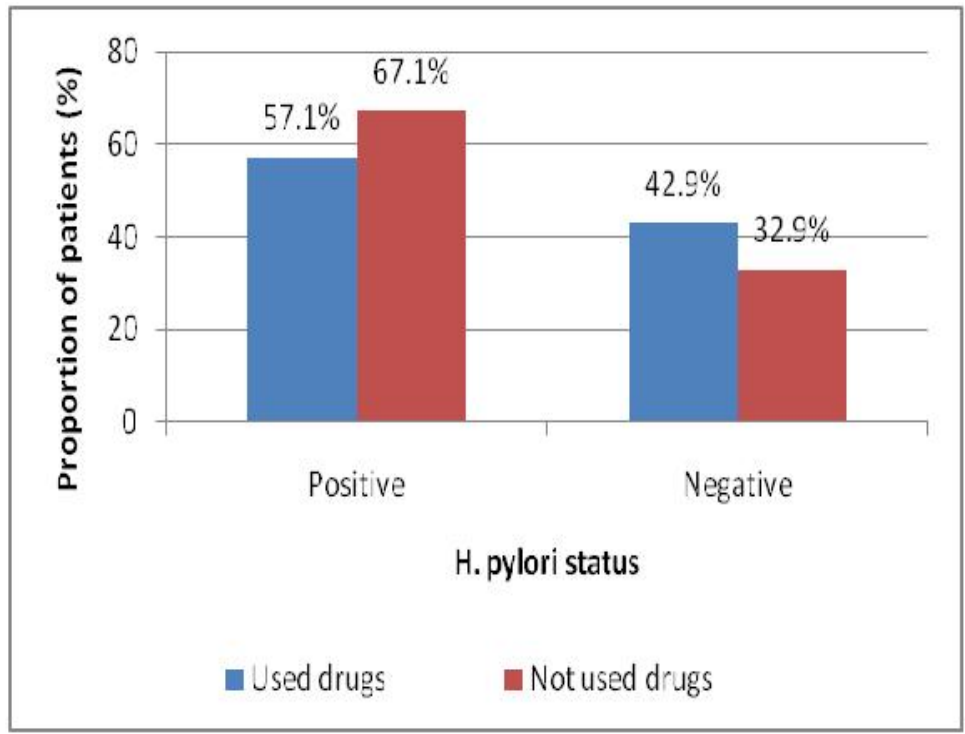

Figure 2: Relationship between use of eradication therapy and RUT results $(n=200)$

Out of 127 patients with Gastritis, 94 (72\%) were positive for $\mathrm{H}$. pylori infection. The presence of Gastritis was statistically significantly associated with diagnosis of $\mathrm{H}$. pylori infection $(\mathrm{OR}, 2.9,95 \% \mathrm{Cl}$ 1.6-5.4, $\mathrm{p}<0.001)$. Among 38 patients with duodenal ulcer, 34 (89.5\%) were infected with $\mathrm{H}$. pylori and the association between presence of duodenal ulcer and $\mathrm{H}$. pylori infection was statistically significant (OR, 5.8; 95\% Cl, 1.98-17.25, p < 0.001). However, H. pylori infection was not significantly associated with GERD, gastric ulcer and gastric cancer $(p>0.05)$ (Table 2$)$. 
Table 2: Relationship between upper gastro-intestinal lesions and $\boldsymbol{H}$. pylori infection among patients with dyspepsia ( $\mathrm{N}=200)$

\begin{tabular}{llllll} 
Endoscopic findings & $\begin{array}{l}\text { H. pylori status } \\
\text { Positive }(\mathbf{N = 1 3 0 )} \\
\mathbf{N}(\%)\end{array}$ & $\begin{array}{l}\text { Negative (N=70) } \\
\mathbf{N}(\%)\end{array}$ & $\begin{array}{l}\text { Total } \\
\mathbf{N}(\%)\end{array}$ & P-value & OR (95\% Cl) \\
& $94(72)$ & $33(28)$ & $127(63.5)$ & $<0.001$ & $2.9(1.60-5.37)$ \\
Gastritis & $81(66)$ & $41(44)$ & $122(58.7)$ & 0.605 & $1.2(0.65-2.12)$ \\
$\begin{array}{l}\text { Gastro-esophageal reflux } \\
\text { disease }\end{array}$ & $34(89)$ & $4(11)$ & $38(19)$ & $<0.001$ & $5.8(1.98-17.25)$ \\
$\begin{array}{l}\text { Duodenal ulcer } \\
\text { Duodenitis }\end{array}$ & $22(69)$ & $10(31)$ & $32(16)$ & 0.627 & $1.2(0.54-2.75)$ \\
Gastric cancer & $8(58)$ & $6(42)$ & $14(7)$ & 0.523 & $0.7(0.23-2.10)$ \\
Esophageal candidiasis & $8(62)$ & $5(48)$ & $13(6.5)$ & 0.787 & $0.9(0.27-2.71)$ \\
Gastric ulcer & $6(50)$ & $6(50)$ & $12(6)$ & 0.261 & $0.5(0.16-1.66)$ \\
\hline
\end{tabular}

\section{Discussion}

In resource limited settings, especially when access to endoscopy service is limited, it is very important for clinicians to know common causes of dyspepsia and frequency of $\mathrm{H}$. pylori infection. In our study, most of the dyspeptic patients had organic causes which were diagnosed with endoscopy. This is consistent with the findings of the studies done in Ethiopia (Asrat et al., 2004) and Nigeria (Mustafa et al., 2007) where organic causes of dyspepsia were documented in $96.4 \%$ and $82.1 \%$ of dyspeptic patients, respectively. However, our finding differs from that of (Tytgat et al. 2002) where meta-analysis of 22 studies from the developed countries showed abnormal endoscopic findings in only $51 \%$ of dyspeptic patients. The differences may be attributed to how patients were selected and in the inclusion and exclusion criteria used in different studies (Marshall \& Winsdor, 2005), differences in socioeconomic status, and health care seeking behavior.

Gastritis and peptic ulcer diseases were found to be common causes of morbidity in Tanzanian patients. Moreover, this study also demonstrated the expected relationship between duodenal ulcer and $H$. pylori infection as reported in other studies from Africa and elsewhere (Ogotu et al., 1998; Ndububa et al., 2001; Suerbaum \& Michetti, 2002; Asrat et al., 2004; Mustafa et al., 2007;). There is ample evidence regarding the beneficial role of $H$. pylori eradication therapy in patients with PUD and gastritis (Hopkins et al., 1996; Gaby, 2001; Yi-Chia et al., 2008). Thus, clinicians should test and treat for the infection if resources are available. In resource poor settings where confirmatory test is not available or may not be cost-effective, empirical therapy is recommended (World Gastroenterology Guidelines, 2010).

The association between $\mathrm{H}$. pylori infection and gastric ulcer and gastric cancer was not statistically significant. This is likely due to small number of patients with gastric ulcer and cancer in this study. Slightly over half of the patients with dyspepsia had endoscopic evidence of GERD in our study. This is consistent with the findings of (Mustafa et al., 2007) from Nigeria who reported esophagitis in two-thirds of dyspeptic patients. However, earlier studies from Ethiopia (Asrat et al., 2004) and Kenya (Ogotu et al., 1998) reported GERD in only $1 \%$ and $4.2 \%$ of dyspeptic patients respectively. An increase in prevalence of GERD has been reported from developed countries (Pandolifino et al., 2004). Our findings could be an indicator of change in pattern of upper GI diseases in Tanzania which is similar to trends reported from Kenya (Hudson et al., 2005) and Asian countries (Ho et al., 2005; Lim et al., 2005). Possible contributing factors for the increase in frequency of GERD include rising obesity rates, increasing life span, change of food habits, and consumption of medications affecting esophageal function and improving health seeking behavior.

Upper $\mathrm{GI}$ malignancies were identified in $8.6 \%$ of the dyspeptic patients. Of these, gastric cancer and distal esophageal cancer were identified in $6.7 \%$ and $1.9 \%$ patients respectively. Gastric 
cancer was found only in patients aged 40 years and above and this difference was statistically significant. The frequency of Gastric cancer in the present study is consistent with the findings of Ogotu et al., 1998, from Kenya but higher than other reported from other studies in Africa (Asrat et al., 2004; Mustafa et al., 2007) and other studies from developed countries (Tytgat, 2002). This may be attributed to mountainous nature of the study site where risk of gastric cancer was reported to be high due to lack of trace minerals in volcanic soils (Bourdenx et al., 1983). It may also be due to differences in genotypes of $H$. pylori which are more carcinogenic (Axon, 1999).

In this study about two-thirds of the dyspeptic patients had $\mathrm{H}$. pylori infection. This is lower compared to findings of a previous study in Tanzania (Kazuo et al., 2004) and other studies from elsewhere in Africa (Ogotu et al., 1998; Ndububa et al., 2001; Asrat et al., 2004; Oladejo et al., 2004; Mustafa et al., 2007). This lower prevalence of the infection is probably due to improvements in sanitation and water supply over the past decades as well as increased awareness and the widespread use of antibiotic therapy. Despite several reports suggesting decreasing prevalence of the infection (Rothenbacher \& Brenner, 2003; Xia et al., 2005; Tkachenko et al., 2007; Kate et al., 2009) clinicians working in developing countries should still consider $\mathrm{H}$. pylori as important etiologic agent.

We found that more than half of patients who underwent RUT after receiving the commonly used eradication regimen ('Triple therapy') still had the infection. Interpretation of this finding is limited by the small number of patients, lack of sensitivity testing and difficult of assessing medication compliance. Conversely, this observation would be of immense concern as resistance of $\mathrm{H}$. pylori to antibiotics is increasingly being reported worldwide. For instance, Metronidazole (the most frequently used drug by our patients), is also used to treat common parasitic and anaerobic bacterial infections; often empirically. Accordingly, studies from India and Senegal documented $\mathrm{H}$. pylori resistance to metronidazole (Datta et al., 2005; Seck et al., 2009). Thus, the concern and uncertainty about our observation requires elaboration by further studies to evaluate the prevalence of $H$. pylori resistance to commonly used antimicrobial agents.

In conclusion, the present study confirms that gastro-duodenitis, peptic ulcer disease, GERD, and gastric cancer are the most common aetiologies of dyspepsia. H. pylori infection is still present in significant proportion of dyspeptic patients. It is also important to note the high prevalence of GERD. In view of the high frequency of gastric cancer we recommend EGD for initial work up of dyspeptic patients over 40 years of age. Due to presence of $H$. pylori infection in significant number of patients who completed eradication therapy, further studies on susceptibility pattern of $H$. pylori are needed to guide clinicians' choice for evidence based eradication regimens.

\section{Competing interests}

The authors declare that they have no competing interests.

\section{References}

Aoki, K., Kihaile, P.E., Castro, M., Disla, M., Nyambo, T.B. \& Misumi, J. (2004) Seroprevalences of Helicobacter pylori Infection and Chronic Atrophic Gastritis in the United Republic of Tanzania and the Dominican Republic. Environmental Health and Preventive Medicine 9, 170-175.

Asrat, D., Nilsson, I., Mengistu, Y., Ashenafi, S., Ayenew, K., Abu al-soud, W., Wadstro“" T. \& Kassa, E. (2004) Prevalence of $\mathrm{H}$. pylori infection among adult dyspeptic patients in Ethiopia. Annals of Tropical Medicine \& Parasitology 98, 181-189.

Axon, A. (1999) Are all Helicobacter equal? Mechanisms of gastroduodenal pathology and their clinical implications. Gut 45, 11-14. 
Blaser, M.J. (1995) The role of Helicobacter pylori in gastritis and its progression to peptic ulcer disease. Alimentary Pharmacology and Therapeutics 9, 27-30

Bourdenx, L., Renard. F., Gigase, P.L., Mukolo-Ndjolo, P., Maldague, P. \& De Muynck, A. (1988) L'incidence des cancers a l'hopital de Katana, Kivu Est. Zaire de 1983 a 1986. Annales de la Societe Belge de Medecine Tropicale 68, 141-156.

Brown, L.M. (2000) Helicobacter pylori: epidemiology and routes of transmission. Epidemiology Review 22: 283-297.

Datta, S., Chattopadhyay, S., Patra, R., De, R., Ramamurthy, T., Hembram, J., Chowdhury, A, Bhattacharya, S.K., Berg, D.E., Nair, G.B. \& Mukhopadhyay, A.K. (2005) Most Helicobacter pylori strains of Kolkata in India are resistant to metronidazole but susceptible to other drugs commonly used for eradication and ulcer therapy. Alimentary Pharmacology \& Therapeutics 22, 51-57.

Fischbach, W., Goebeler-Kolve, M.E., Dragosics, B., Grenier, A. \& Stolte, M. (2004) Long term outcome of patients with gastric marginal zone B cell lymphoma of mucosa associated lymphoid tissue (MALT) following exclusive Helicobacter pylori eradication therapy: experience from a large prospective series. Gut 53, 34-37.

Frenck, R.W. Jr \& Clemens, J. (2003) Helicobacter in the developing world. Microbes and Infectioin 5, 705713.

Gaby, A. (2001) Helicobacter pylori eradication: are there alternatives to antibiotics? Alternative Medicine Review 6,355-366.

Go, M.F. (2002) Natural history and epidemiology of Helicobacter pylori infection. Alimentary Pharmacology \& Therapeutics 16, 3-15.

Graham, D.Y. (1994) Benefits from elimination of Helicobacter pylori infection include major reduction in the incidence of peptic ulcer disease, gastric cancer, and primary gastric lymphoma. Preventive Medicine 23, 712-716.

Hildebrand, P., Bardhan, P., Rossi, L., Parvin, S., Rahman, A., Arefin, M.S., Hasan, M., Ahmad, M.M., GlatzKrieger, K., Terracciano, L., Bauerfeind, P., Beglinger, C., Gyr, N. \& Khan, A.K. (2001) Recrudescence and re-infection with Helicobacter pylori after eradication therapy in Bangladeshi adults. Gastroenterology 121, 792-779.

Ho, K.Y., Chan, Y.H. \& Kang, J.Y. (2005) Increasing trend of reflux esophagitis and decreasing trend of Helicobacter pylori infection in patients from a multiethnic Asian country. American Journal of Gastroenterology 100, 1923-1928.

Hopkins, R.J., Girardi, L.S. \& Turney, E.A. (1996) Relationships between H. pylori eradication and reduced duodenal and gastric ulcer recurrence: A review. Gastroenterology 110, 1244-1252.

Hunt, R.H., Xiao, S.D., Megraud, F., Leon-Barua, R., Bazzoli, F., van der Merwe, S., Vaz Coelho, L.G., Fock, M., Fedail, S., Cohen, H., Malfertheiner, P., Vakil, N., Hamid, S., Goh, K.L., Wong, B.C., Krabshuis, J., Le Mair, A. (2011) Helicobacter pylori in developing countries. World Gastroenterology Organization Global Guidelines. Journal of Gastrointestinal and Liver Diseases 20, 299-304.

Jemilohun, A.C. \& Fadare, J.O. (2013) Dyspepsia management in a resource poor setting. Annals Ibadan Postgraduate Medicine 11, 2-6.

Kibiki, G.S., Maro, V.P., Sam, N.E., Dolmans, W.M. \& Crump, J.A. (2006) Hookworm infection of the duodenum associated with dyspepsia and diagnosed by oesophagoduodenoscopy: case report. East African Medical Journal 83: 689-692.

Lawal, O., Rotimi, O. \& Okeke, I. (2007) Helicobacter pylori in Gastroduodenal diseases.Lie-ife, Osun State, Nigeria. Journal of the National Medical Association 99, 1. 
Lee, Y., Liou, J., Wu, M., Wu, C. \& Lin, J. (2008) Eradication of Helicobacter pylori to prevent gastroduodenal diseases: hitting more than bird with the same stone. Therapeutic Advances in Gastroenterology 1, 111-120

Lim, S.L., Goh, W.T., Lee, J.M., Ng, T.P. \& Ho, K.Y. (2005) Community medical gastrointestinal study Group. Changing prevalence of gastroesophageal reflux with changing time: Longitudinal study in an Asian population. Journal of Gastroenterology and Hepatology 20, 995-1001.

Lodenyo, H., Rana, F., Mutuma, G.Z., Kabanga, J.M., Kuria, J.K. \& Okoth, F.A. (2005) Patterns of upper gastrointestinal diseases based on endoscopy in the period 1998-2001. African Journal of Health Sciences 12, 49-54.

Mandeville, K.L., Krabshuis, J., Ladep, N.G., Mulder, C.J.J., Quigley, E.M.M. \& Khan, S.A. (2009) Gastroenterology in developing countries: Issues and Advances. World Journal of Gastroenterology 15, 2839-2854.

Marshall, B.J. \& Windsor, H.M. (2005) The relation of Helicobacter pylori to gastric adenocarcinoma and lymphoma: pathophysiology, epidemiology, screening, clinical presentation, treatment, and prevention. Medical Clinics of North America 89,313-344.

Mustapha, S.K., Bolori M.T., Ajayi N.A., Nggada H.A., Pindiga U.H., Gashau W. \& Khalil, M.I.A. (2007) Endoscopic findings and the frequency of Helicobacter pylori among dyspeptic patients in northeastern Nigeria. The Internet Journal of Gastroenterology 6 (1).

Ndububa, D.A., Abakwuru, A.E. \& Adebayo, R.A. (2001) Upper gastrointestinal findings and incidence of $H$. pylori infection among Nigerian patients with dyspepsia. West African Journal Medicine 20, 140145.

Ogutu, E.O., Kang'ethe, S.K., Nyabola, L. \& Nyong'O, A. (1998) Endoscopic findings and prevalence of Helicobacter pylori in Kenyan patients with dyspepsia. East African Medical Journal 75, 85-89.

Pandolfino, J.E., Howden, C.W., Kahrilas, P.J. (2004) H. pylori and GERD: is less or more? American Journal of Gastroenterology 99, 1222-1225.

Rollan, A., Giancaspero, R., Fuster, F., Acevedo, C., Figueroa, C., Hola, K., Schulz, M. \& Duarte, I. (2000) The long-term re-infection rate and the course of duodenal ulcer disease after eradication of Helicobacter pylori in a developing country. American Journal Gastroenterology 95, 50-56.

Rothenbacher, D. \& Brenner, H. (2003) Burden of Helicobacter pylori and H. pylori-related diseases in developed countries: recent developments and future implications. Microbes and Infection 5, 693703.

Seck, A., Mbengue, M., Gassama-Sow, A., Diouf, L., Ka, M.M. \& Boye, C.S. (2009) Antibiotic susceptibility of Helicobacter pylori isolates in Dakar, Senegal. Journal of Infection in Developing Countries 3, 137140.

Stolte, M., Bayerdorffer E. \& Morgner, A. (2002) Helicobacter and gastric MALT lymphoma. Gut 50 (Suppl 3), 19-24.

Suerbaum, S. \& Michetti, P. (2002) Helicobacter pylori infection. New England Journal Medicine 347, 11751186.

Tkachenko, M.A., Zhannat, N.Z., Erman, L.V., Blashenkova, E.L., Isachenko, S.V., Isachenko, O.B., Graham, D.Y. \& Malaty, H.M. (2007) Dramatic changes in the prevalence of Helicobacter pylori infection during childhood: a 10-year follow-up study in Russia. Journal of Pediatric Gastroenterology and Nutrition 45, 428-432.

Tytgat, G.N.J. (2002) Role of endoscopy and biopsy in the work up of Dyspepsia. Gut 50 (Suppl IV), iv13-iv16.

Wong, B.C., Lam, S.K., Wong, W.M., Chen, J.S., Zheng, T.T., Feng, R.E., Lai, K.C., Hu, W.H., Yuen, S.T., Leung, S.Y., Fong, D.Y., Ho, J., Ching, C.K., Chen, J.S. \& China Gastric Cancer Study Group (2004) Helicobacter pylori eradication to prevent gastric cancer in a high-risk region of China: a randomized controlled trial. Journal of American Medical Association 291, 187-194. 
Xia, B., Xia, H.H., Ma, C.W., Wong, K.W., Fung, F.M., Hui, C.K., Chan, C.K., Chan, A.O., Lai, K.C., Yuen, M.F. \& Wong, B.C. (2005) Trends in the prevalence of peptic ulcer disease and Helicobacter pylori infection in family physician-referred uninvestigated dyspeptic patients in Hong Kong. Alimentary Pharmacology \& Therapeutics 22, 243-249. 